https://artnodes.uoc.edu

\title{
La anamorfosis en el arte contemporáneo. Un análisis de las diferentes estrategias de su aplicación en las creaciones de artistas actuales
}

\author{
Jose-Antonio Soriano-Colchero \\ Universidad de Granada
}

Fecha de presentación: febrero de 2021

Fecha de aceptación: marzo de 2021

Fecha de publicación: julio de 2021

\section{Cita recomendada}

Soriano-Colchero, Jose-Antonio. 2021. «La anamorfosis en el arte contemporáneo. Un análisis de las diferentes estrategias de su aplicación en las creaciones de artistas actuales». Artnodes, núm. 28. UOC. [Consulta: dd/mm/aa]. http://doi.org/10.7238/a.v0i28.381600

\section{(C)} SORTERIGHIS RESERVED
Los textos publicados en esta revista están sujetos -si no se indica lo contrario- a una licencia de Reconocimiento 4.0 Internacional de CreativeCommons. La licencia completa se puede consultar en https://creativecommons.org/licenses/by/4.0/deed.es_ES.

\section{Resumen}

La anamorfosis es una variante de la perspectiva matemática estudiada por artistas e intelectuales europeos desde el siglo xvl, y se alcanzó la publicación del método definitivo en el siglo xvı. Su original aura misteriosa sería sustituida, debido a la consideración sobre las imágenes a las que se le aplicaba, por mero entretenimiento tras su popularización durante el siglo xvill, mediante los gabinetes de curiosidades y Kunst-und Wunderkammeern. No obstante, la anamorfosis ha continuado estudiándose y aplicándose a proyectos de creación artística. Así, el objetivo de la presente publicación es el desarrollo de una actualización sobre cómo la anamorfosis es aplicada al arte contemporáneo a través del estudio de numerosas obras, evidenciando las posibilidades técnicas y conceptuales que este sistema ofrece tanto al arte en sí como a la sociedad en general a través de este. Todas las obras analizadas-relacionadas 


\title{
artnodes
}

https://artnodes.uoc.edu

La anamorfosis en el arte contemporáneo. Un análisis de las diferentes estrategias de su aplicación en las creaciones de artistas actuales

con la anamorfosis óptica y catóptrica a través de la escultura, la fotografía y la pintura de artistas callejeros 0 relacionados a las galerías de arte- propician un discurso que invita a la reflexión sobre la realidad contemporánea o hiperrealidad. Con ello, damos a conocer el método de la anamorfosis, además de incentivar a los artistas visuales a aplicarlo en futuras creaciones, dado el interés que genera el método por su versatilidad en cuanto a potencial metodológico y de significación, demostrado en el cuerpo del artículo y en las conclusiones. La imagen anamórfica es entendida, por lo tanto, como metaimagen que evidencia su propia artificiosidad, incitando al observador a reflexionar sobre la realidad y exigiendo nuevas formas de interpretar lo observado.

\section{Palabras clave}

anamorfosis, trampantojo, quadratura, arte contemporáneo, ilusión óptica.

\section{Anamorphosis in contemporary art: Analysing new ways for its application in art projects by current artists}

\begin{abstract}
Anamorphosis is a variant of the mathematic perspective studied by European artists and intellectuals since the 16th century, its definite method being published in the 17th century. The aura of mystery linked to this representational system was substituted by the thought that these images were a product of pure entertainment after they became popular during the 18th century thanks to the cabinet of curiosities and Kunst-und Wunderkammern. In spite of this, anamorphosis has continued to be studied and used in artistic projects. The main objective of this work is to offer updated information about how anamorphosis is used in contemporary art by studying numerous works and show-casing the possible techniques and concepts this system offers not only to art itself, but also to society. All works analysed -related to optic and catoptric anamorphosis in sculpture, photography and paintings of street artists or from art galleries - contribute to a debate that invites us to reflect on contemporary reality or hyper-reality. Likewise, this article shows what the method to produce anamorphosis is and motivates visual artists to use it in their future creations, due to the interest it attracts thanks to its versatility of potential, in method and significance, as proved in the main article and conclusions. Therefore, anamorphosis is understood as a meta-image that demonstrates the artificiality of the image itself, inviting the observer to reflect on reality and requiring new ways to interpret what has been seen.
\end{abstract}

\section{Keywords}

Anamorphosis, Trompe l'eoil; Quadratura; Contemporary art, Optical illusion.

\section{Introducción}

La anamorfosis es un sistema de representación derivado de la perspectiva matemática en su posibilidad más extrema, pues implica deformaciones. Mientras que con las imágenes consideradas como quadrature los creadores pretenden generar una ilusión visual constante -ejemplo de ello son las representaciones de la bóveda y la falsa cúpula de la iglesia de San Ignacio en Roma, diseñadas por Andrea Pozzo entre 1685 y 1689-, las imágenes anamórficas son creadas para establecer un juego de interactuación entre obra y observador, ya que resultan difíciles de reconocer desde la mayoría de puntos de vista, exceptuando el punto de proyección en el que se puede experimentar una fugaz ilusión visual. Es el caso de los murales del convento de
Trinità dei Monti en Roma por Emmanuel Maignan y Jean François Niceron, 1641 y 1642 respectivamente, 0 de la pintura sobre tabla de Hans Holbein el Joven, Los Embajadores, 1533, en la National Gallery de Londres.

Durante el siglo xvı existirían estudios de perspectiva en los que se trataría sobre la deformación de imágenes sin el establecimiento de un método concreto, por autores como Da Vinci (1478-1519), Lomazzo (1585), Barbaro (1568) o Vignola y Danti (1583). Ya en el siglo xvII se Ilegaría a la difusión de una metodología concreta de forma progresiva a través de autores como Salomon de Caus (1612), Andreas Albrecht (1623), Niceron (1638) (1646), Maignan (1648), Kircher (1646), Du Breuil (16421649) y Schott (1657). En los tratados, las imágenes anamórficas toman relevancia en cuanto a sus cualidades técnicas, pero, con 


\section{artnodes}

https://artnodes.uoc.edu

relación al arte, serán los mismos aspectos característicos de la pintura barroca los que identifiquemos en ellas: escenografía, relación entre observador e imagen, y el movimiento. Además, el contenido conceptual de estas imágenes sería muy variado: experimental o didáctico, religioso, político y cómico o satírico (Pino-León, 2014). Las imágenes anamórficas también serían un reclamo en los gabinetes de curiosidades barrocos y posteriores, y se popularizarían, adquiriendo un carácter lúdico muy alejado de su relación con los métodos científicos y misteriosos que en un principio las caracterizarían.

Actualmente, la anamorfosis es un sistema aplicado desde diferentes estrategias en el arte contemporáneo, diferenciando un tipo de arte que juega alterando la percepción espacial y desarrollando un discurso acerca de la veracidad de lo observado. Consideramos especialmente relevante esto debido a los datos que recibimos actualmente a través de los medios de comunicación audiovisuales. Tras referenciar al mito de la caverna de Platón y su ciudad de la verdad, Byung-Chul Han describe así esta relación entre nuestra sociedad -de la transparencia- actual y la información recibida: «Es el poeta el que produce las ilusiones escénicas, las formas aparentes, los signos rituales y ceremoniales, y contrapone los artefactos y antifactos a lo hiperreal, a los hechos desnudos» (Han, 2015: 76). Esta teoría queda estrechamente vinculada a los conceptos de simulacro e hiperrealidad de Baudrillard $(2005,2006)$ o la sociedad del espectáculo de Debord (2012). Ante la carencia de objetividad plena y veracidad en las múltiples informaciones recibidas a través de las imágenes (Sartori, 2008; Fontcuberta, 2016: 401), podemos considerar la confluencia de posibilidades para dar explicación a los sucesos, como apoyaría Vattimo: «Realidad, para nosotros, es más bien el resultado de entrecruzarse [...] de las múltiples imágenes, interpretaciones y reconstrucciones que compiten entre sí, o que, de cualquier manera, sin coordinación "central" alguna, distribuyen los media» (Vattimo, 1996: 81). Así, la anamorfosis invita al observador a analizar la realidad desde múltiples puntos de vista, más allá del que queda establecido, desde el cual toda explicación e imagen carece de distorsiones que alteren la aparente objetividad de estas. De esta forma, la reflexión sobre lo que observamos puede ayudarnos a ver más allá de la «[...] estetización excesivamente parasitada por las lógicas del consumo y apoyada en estrategias de seducción [....]» (Martín Prada, 2012: 112) propias de las imágenes contemporáneas. Dadas las posibilidades discursivas y conceptuales que ofrece la anamorfosis, el objetivo de nuestro estudio consiste en una actualización de cómo esta se ha aplicado a la práctica artística contemporánea, por lo que resulta imprescindible
La anamorfosis en el arte contemporáneo. Un análisis de las diferentes estrategias de su aplicación en las creaciones de artistas actuales

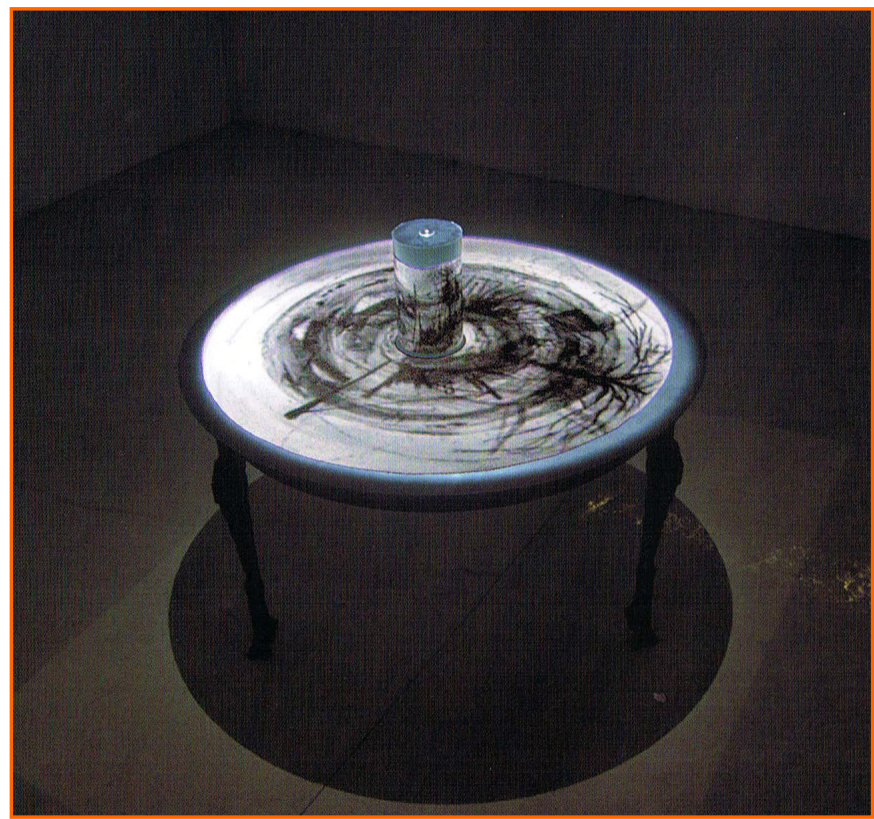

Figura 1. William Kentridge. What will come (has already come), 2007. Videoproyección anamórfica, película de $35 \mathrm{~mm}$ transferida a DVD. 9' 14", cilindro metálico, mesa de hierro de $130 \mathrm{~cm}$ de diámetro y $7 \mathrm{~cm}$ de altura. Edición de 14. CWilliam Kentridge. (Kentridge, Francés, y Corral, 2012: 130).

referenciar el artículo de Collins (1992) en el que se desarrolla un listado de artistas del siglo $\mathrm{xx}$-principalmente obras expuestas a partir de los años sesenta-, así como la tesis doctoral de López Montero (1995), en la que se estudian las diferentes estrategias técnicas a través de numerosos ejemplos históricos.

Adelantamos que la anamorfosis óptica predomina sobre la catóptrica -para la cual resulta imprescindible el empleo de un espejo cóncavo, convexo o plano, que ofrezca el reflejo sin distorsión de la imagen anamórfica representada en otro plano, estructurada según unos patrones o plantillas adecuadas a la superficie que refleja-. En algunos casos estas segundas no resultan demasiado relevantes en proporción al resto de producción de determinados artistas, como sucede con las piezas: Echo activity, 2018, de Olafur Eliasson; Selfportrait (Anamorphic), 2007, de Chuck Close; o What Will Come (Has Already Come), 2007, de William Kentridge [figura 1], caracterizada por la innovación que supone crear animaciones encajadas en las plantillas cilíndricas de Du Breuil (1642-1649: 138). Por lo contrario, los artistas Felice Varini, Istvan Orosz ${ }^{2}$ y Jonty Hurwitz cuentan con numerosas anamorfosis catóptricas entre sus creaciones, como Miroir à $180^{\circ}$ avec anneau orange autor du sol, 2002; A magically appearing portrait of

1. El término postfotografía de Fontcuberta designa al conjunto de fotografías actuales cuya relación con una posible realidad queda reducida por la multitud de ejemplares que dan respuesta a la demanda de contenidos inmediatos en carencia de la calidad.

2. Sus dibujos anamórficos son reconocibles únicamente desde el reflejo de un cilindro metálico que elimina las distorsiones originales del dibujo, como también sucede en trabajos de Hans Hamngren. 


\section{artnodes}

https://artnodes.uoc.edu

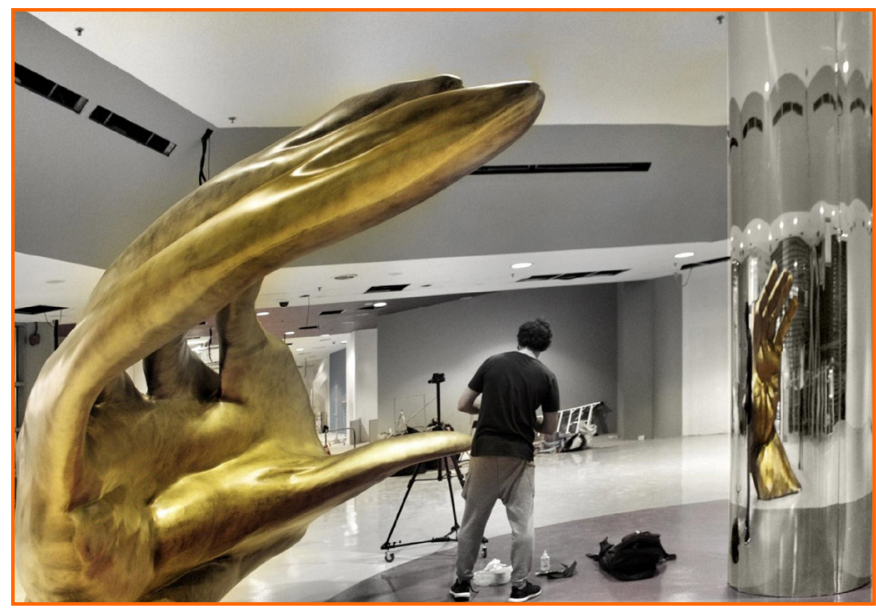

Figura 2. Jonty Hurwitz, Mother's hand, 2017. Resina, fibra de vidrio y acero inoxidable. OJonty Hurwitz. (Hurwitz, S. F). Fuente: https://jontyhurwitz.com/mothers-hand-jontyhurwitz.

Jules Verne on the Myserious Island, 1983; y Mother's hand, 2017, respectivamente [figura 2]. Este último caso resulta muy original por la incorporación de las distorsiones a la escultura.

Precisamente dependiendo de la modalidad artística a la que se aplica la anamorfosis, así como a las características técnicas y formales de las diferentes obras que estudiaremos, estableceremos la clasificación en los siguientes apartados. En primer lugar, trataremos sobre la anamorfosis óptica en la escultura y la fotografía contemporáneas. Su aplicación a la pintura será desarrollada posteriormente. $Y$ dada la gran variedad de trabajos existentes, estableceremos una clasificación interna entre figuración y abstracción, a partir de las cuales diferenciamos entre las obras relacionadas con la galería de arte -expuestas en el interior 0 en el exterior-y las de entornos públicos por parte de los artistas callejeros. Estos criterios de clasificación son establecidos para evidenciar las versátiles posibilidades que ofrece este sistema para aplicarse a diferentes modalidades artísticas.

\section{La anamorfosis óptica y sus posibilidades en la escultura y la fotografía contemporáneas}

La aplicación de la anamorfosis óptica al volumen puede encontrarse en los experimentos del científico Adelbert Ames Jr., autor de la Habitación de Ames, 1946; y otros ejemplos como el Cajón de Madera, 1975, de Beutner; 0 la pieza titulada Retrato de Pierre Wissant, 1983, de Dominique Tordjman -entre otros casos recogidos en estudios sobre anamorfosis (López Montero, 1995: 476-487; Cabezas Jiménez, 2007: 191-194)- que pudieron funcionar como referentes para la escultura Ellipse sans titre, 2018, del artista Felice Varini, o para las numerosas obras del escultor hiperrealista Evan Penny, entre las que destacamos Self, 2008; Michael, Variation \#3, 2010; Jim Revisited,
La anamorfosis en el arte contemporáneo. Un análisis de las diferentes estrategias de su aplicación en las creaciones de artistas actuales

2011; y Homage to Holbein, 2016, clara referencia a dos pinturas de Holbein el Joven (Short, 2017: 6.o párrafo). Desde una metodología diferente trabaja el artista Michael Murphy, pues en sus instalaciones el volumen se expande en el espacio. Destacamos su pieza titulada The Immigrant - A tribute to immigrants, 2019, que, vista desde un punto predeterminado por el artista, adquiere la forma de un retrato femenino que aparentemente flota en el espacio y que se diluye a medida que nos alejamos de dicho punto (Murphy, 2019) [figura 3]. Este tipo de anamorfosis óptica fue representada en algunas pinturas de Salvador Dalí, como Galatea de las esferas, 1952, quien era conocedor de la metodología y la aplicó a algunas de sus obras.

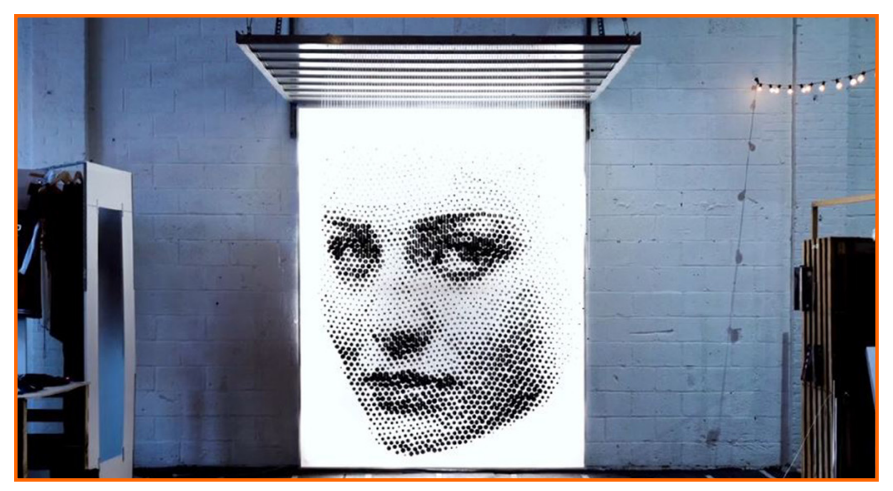

Figura 3. Michael Murphy, The Immigrant - A tribute to immigrants, 2019. 2300 bolas de madera. @Michael Murphy. (Murphy, 2019).

También se disponen en el espacio una serie de piezas de Tim Noble y Sue Webster, pero en estos casos la imagen reconocible es dada a partir de la sombra de una escultura que genera un foco de luz situado en el punto de proyección. Si el observador colocase uno de sus ojos en la misma posición que dicho foco, sería capaz de reconocer esa misma silueta en las esculturas, tal y como ocurría al observar el Mickey Mouse del artista Markus Raetz. Creaciones como The Masterpiecce, 2014, hacen reflexionar sobre la veracidad de lo percibido y su correspondencia con la realidad (Noble y Webster, 2005), al igual que piezas de Shigeo Fuduka, como Lunch With a Helmet On, 1978. Y sobre la fugacidad de la vida y la utilidad de los objetos trata el discurso de las piezas de Noah Scalin, creadas para espacios concretos, como Bethino, 2018.

Si bien la fotografía es la modalidad artística de la que menos ejemplos hemos encontrado en su uso para la creación de anamorfosis, no por ello resulta menos interesante. Es muy adecuada para proyectos de gran escala, como el de JR en el Museo del Louvre de París: JR at the Louvre Museum, The Pyramid, 2016, en la que se camufló la pirámide de cristal al suponerse sobre ella una fotografía histórica -previa a la pirámide-, adaptada con anamorfosis, de la fachada principal del Louvre. Se trata de una pieza cuyos referentes directos son los proyectos fotográficos de Felice Varini -al que men- 


\section{artnodes}

https://artnodes.uoc.edu

ciona en el vídeo explicativo de su obra (JR, 2016) - como Octogono au carré, 2003. Otra gran anamorfosis realizada tres años después en el mismo lugar sería JR at the Louvre Museum \& The secret of the Great Pyramid, 2019 [figura 4].

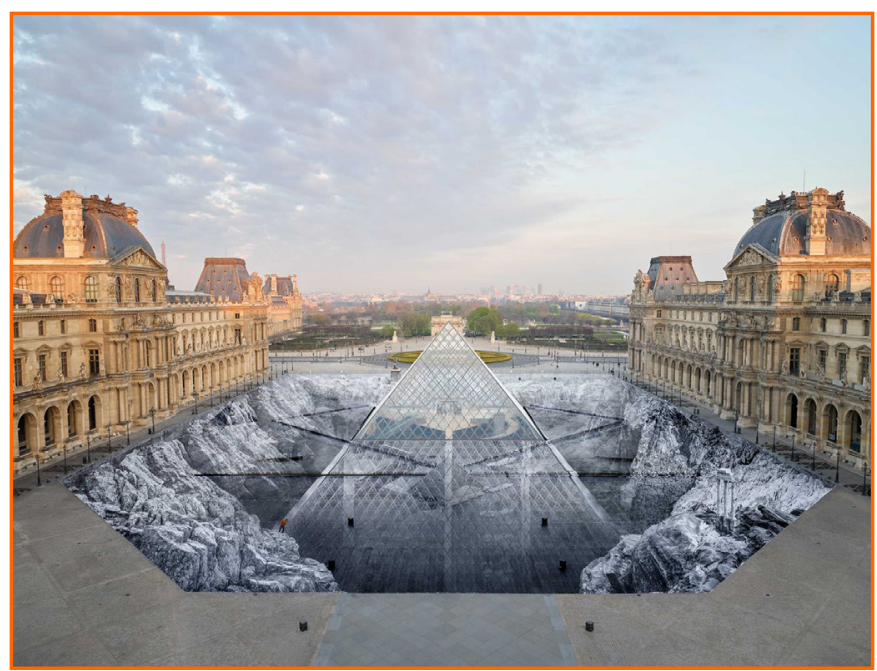

Figura 4. JR, JR at the Louvre Museum \& The secret of the Great Pyramid, 2019. Papel encolado. Museo del Louvre. Paris. @JR Photographer. (JR, S. F). Fuente: https://www.jr-art. net/projects/jr-au-louvre--le-secret-de-la-grande-pyramide

\section{Anamorfosis óptica y sus posibilidades en la pintura contemporánea}

\subsection{Pintura figurativa}

En cuanto a la pintura figurativa en la que se aplica la anamorfosis, diferenciamos las creaciones relacionadas con las galerías de arte y las pertenecientes al arte callejero. Las obras de este segundo grupo tienen lugar mayoritariamente en eventos de diversas escalas, como el Chalk Festival de Florida o el World Street Painting de Arnhem, entre otros. Entre las técnicas encontramos pintura en spray procedente de la pintura grafiti, pastel seco, que sigue la tradición de los madonnari ${ }^{3}$ y otros medios como pintura acrílica. Artistas como Leon Keer trabajan sobre mural, pavimento e incluso espacios naturales, como el proyecto Offline Anamorphic Land Art, 2019, para el Street Painting Festival Arnhem 2019 en Crans-Montana, Suiza (Keer, 2019). Cabe resaltar la interacción con el observador de estas representaciones, pues, aunque toda anamorfosis invita ello, al estar en espacios públicos y transcurridos, estas son más propicias a generar el factor sorpresa, popularizándose.

En la modalidad del pavement chalk painting -pintura a la tiza sobre pavimento-, el principal referente es Kurt Wenner, autorrecono-
La anamorfosis en el arte contemporáneo. Un análisis de las diferentes estrategias de su aplicación en las creaciones de artistas actuales

cido como el creador del concepto 3D Street art (Wenner, 2019). Su trabajo ha evolucionado llegando a construir imágenes de gran escala, como Lost World, 2019, en el aeropuerto de Venice, Florida. Otro referente es Julian Beever, quien comenzó a aplicar la anamorfosis de forma anecdótica para adoptarla posteriormente como una seña de identidad (Beever, 2018). Ambos han trabajado para campañas de publicidad, algo que sucede con la mayoría de los artistas callejeros, como Manfred Stader, Edgar Mueller o Eduardo Relero [figura 5]. En cuanto a la pintura en espray, destacamos a Sergio Odeith o el colectivo Truly, cuyos proyectos son aplicados a espacios interiores. Son muy representativas sus diseños de animales y seres fantásticos, como Griffin, 2016 -de Truly-, instalado en el Magic City Life Festival de Dresden.

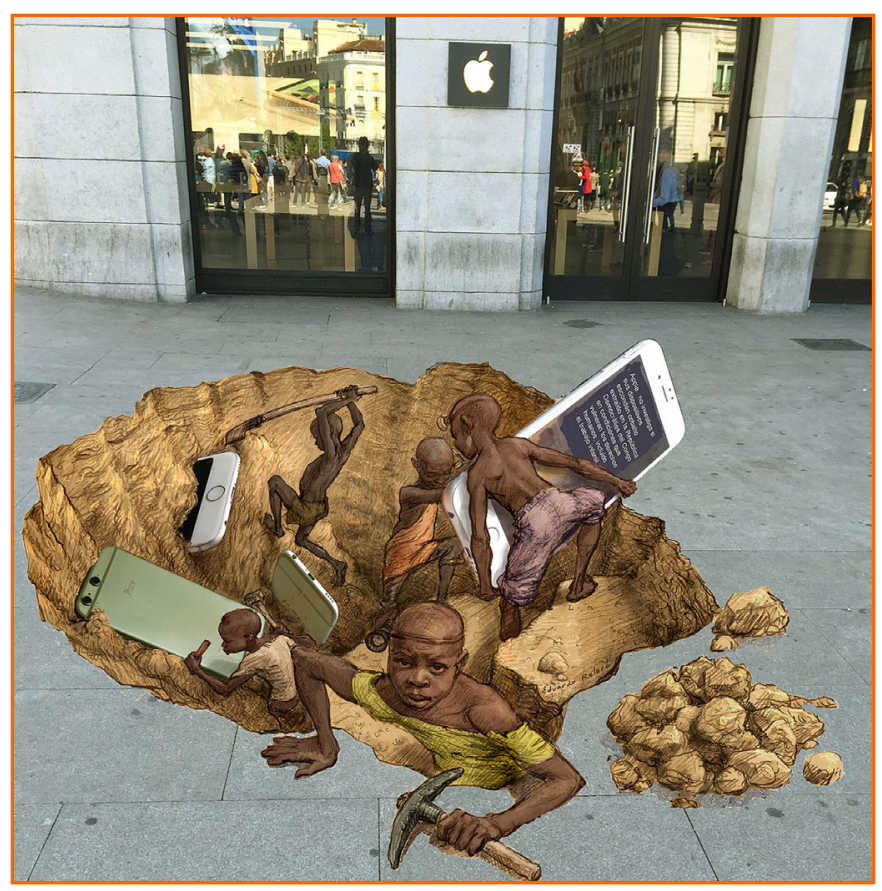

Figura 5. Eduardo Relero, Víctimas de los móviles, 2016. Sol, Madrid. (CEduardo Relero. (AMNISTÍA INTERNACIONAL ESPAÑA, 2020). Fuente: https://www.es.amnesty.org/en-queestamos/noticias/noticia/articulo/apple-mira-hacia-otro-lado-y-no-aclara-si-hay-trabajoinfantil-detras-de-sus-dispositivos/

A diferencia de los artistas callejeros, aquellos que intervienen espacios relacionados a la galería de arte pueden alterar estructuralmente este. Una de las artistas más representativas es Regina Silveira, cuyo interés por la perspectiva procede de la inquietud por conocer mejor el código de las imágenes visuales y la ilusión que estas producen (Silveira, 2005), con lo que resultan en instalaciones como Absentia, 1982; o Super Herói (Night and Day), 1997. Para la artista,

3. Artistas del siglo XVI que realizaban pinturas efímeras de iconos religiosos sobre pavimentos.

4. Arte urbano tridimensional que, según Wenner, surgió en el año 1984. 


\section{artnodes}

https://artnodes.uoc.edu

toda conceptualización de la imagen es fruto de la ilusión visual, lo que señala un enfoque relativista en creaciones como Abyssal, 2010, en el Atlas Sztuki en Polonia [figura 6]. También se altera la percepción espacial en los trabajos anamórficos de Damien Gilley, quien dibuja con cinta adhesiva sobre planos incorporados al espacio arquitectónico original. Destacamos instalaciones como Fortress en Worksound Gallery; Axis Index, en Suyama Space; y 1+1=1, en Disejecta Contemporary Art Center. Igualmente, el artista Igor Skinja trabaja con cinta adhesiva, así como con cables, y su obra final resulta en la fotografía de la instalación desde el punto de proyección. Destacamos Meditations on the Orizon, expuesta en la galería Federico Luger en 2019.

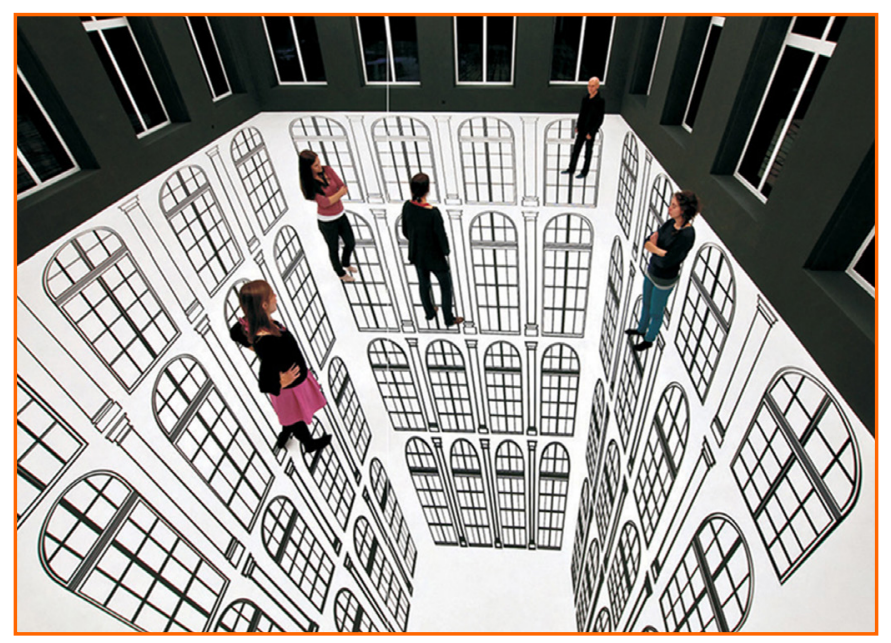

Figura 6. Regina Silveira, Abyssal, 2010. Vinilo adhesivo, paredes pintadas y filtros de luz., Atlas Sztuki, Polonia. @Regina Silveira. (Silveira, S. F). Fuente: https://reginasilveira.com/ABYSSAL

Por otra parte, la anamorfosis puede incorporarse a pinturas sobre tabla o lienzo, siguiendo ejemplos del Retrato del futuro Rey Eduardo VI, 1546, de William Scrots, entre otros de autoría anónima (Hernández-Machancoses, 2015). En algunos casos es aplicada por experimentación, como en la pieza Sin título, 1934-1936, de Luis Fernández (Museo de Bellas Artes de Asturias, 2020); 0 en la serie de retratos Anamorphosen de la artista Anne Bering. En otros casos, la anamorfosis toma más relevancia en la producción de artistas como González Castro, pues le interesa que el observador pueda interactuar con la pintura: «Con la anamorfosis pretendo convertir el cuadro en un objeto que, como una escultura, debe observarse desde más de un punto de vista, esto es, desde el margen del cuadro [...]» (González Castro, 2017). Queda demostrado en series como Anamorfosis, 2013; Doppelgänger, 2014; y 0 tempora, o mores, 2015,
La anamorfosis en el arte contemporáneo. Un análisis de las diferentes estrategias de su aplicación en las creaciones de artistas actuales

en la que introduce subliminalmente elementos considerados como tabú. En su última serie anamórfica, Introspectiva, 2016-2017, ha empleado la distorsión para diferenciar figura de fondo. Ejemplo de ello es Magdalena Penitente [figura 7].

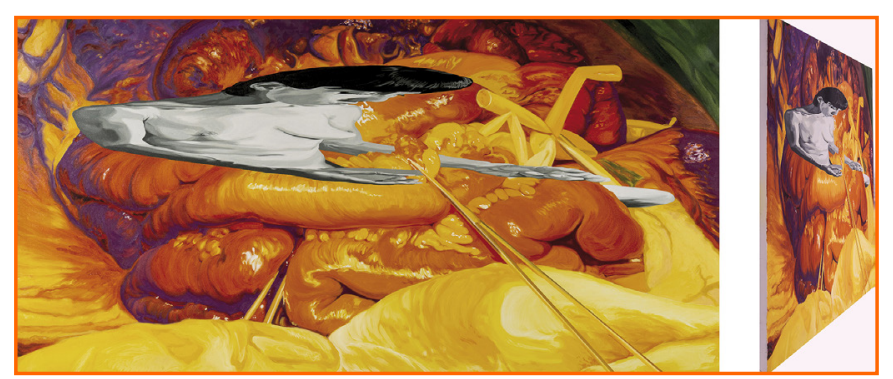

Figura 7. Carmen González Castro, Magdalena Penitente, 2016 - 2017. Óleo sobre lienzo. 73 x $146 \mathrm{~cm}$. (C)armen González Castro. (González-Castro y Vegap, 2018). Recuperado de: http:// carmengonzalezcastro.com/introspectiva-2016-2017/

\subsection{Pintura abstracta}

En cuanto a la anamorfosis abstracta aplicada al espacio urbano, la técnica más empleada es la pintura acrílica por la uniformidad de color que ofrece; pero igualmente se utilizan láminas adhesivas para evitar daños o pintura en espray para conseguir degradados de color. Comenzamos presentando el trabajo del artista Peeta, que altera visualmente las estructuras arquitectónicas de edificios, como sucede con Stadt. Wand. Kunst, 2019 (Peeta, 2015). Continuamos con el colectivo Boa Mistura, quienes utilizan palabras distorsionadas en creaciones como Más allá de los muros, la calle, 2019, que funciona como crítica social (Boa Mistura, s.d.); al igual que el proyecto de Zoer con el que intervino en 2017 la fachada del centro comercial Les Ateliers Gaités de París [figura 8]. No obstante, sus anamorfosis han sido además empleadas para publicitar productos como el perfume LACOSTE L!IVE ${ }^{5}, 2014$.

Entre los trabajos abstractos relacionados con la galería, destacan las pinturas expandidas en el espacio. Uno de los artistas y teóricos más reconocidos en este ámbito -aunque su producción se extiende más allá- es Brian 0'Doherty ${ }^{6}$. Sus anamorfosis incorporan cordones de nailon que dibujan las figuras geométricas pintadas en el muro cuando son observadas desde el punto de proyección. Así ocurre en The doors to good and evil and the Windows to heaven-Christina's world, Rope Drawing \# 124, expuesta en el IMMA de Dublín en 2015. Otro artista, de menor trayectoria, que centra su producción desde los años noventa en la anamorfosis óptica y catóptrica ${ }^{7}$ es Augusto Zanela. Piezas como Damero, 2000; Flechas (variación de la ley de Müller-Lyer), 2001; o Apunte, 2005, reflejan el interés por el sistema (Zanela, 2011).

5. Enlace para visualizar el spot publicitario: https://youtu.be/y/n7oc7qWLU.

6. Conocido hasta 2008 como Patrick Ireland.

7. Flat Lux. 2016. Centro Cultural Recoletas. Exposición individual de Zanela: El primer día. 


\section{artnodes}

https://artnodes.uoc.edu

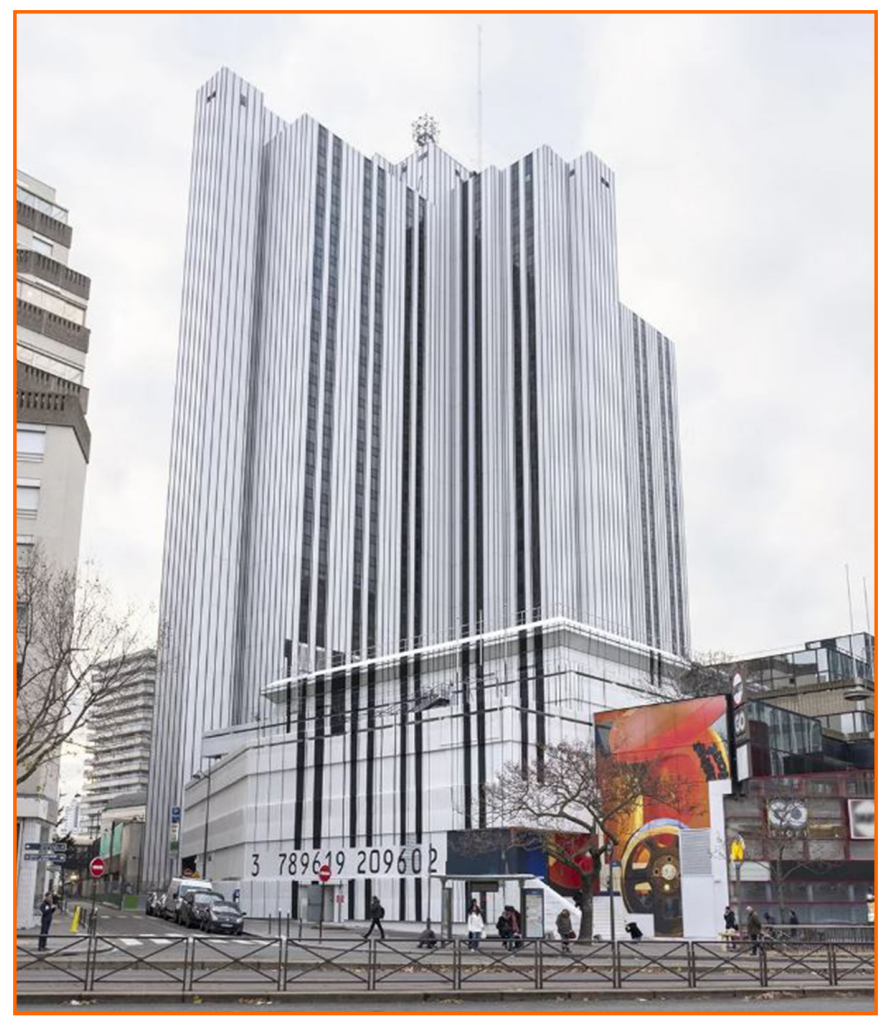

Figura 8. Zoer, Supoort Grande Surface, 2017. Acrilico sobre hormigón. Les ateliers Gaité, París, Francia. OZoer. (Zoer, S. F). Fuente: https://www.zoerism.com/mural-support-grande-surface

A menudo estas instalaciones son comercializadas como fotografías $^{8}$, como haría primeramente Arthur S. Mole. Así sucede con series de Jan Dibbets como Perspective Corrections, 1969; y Perspective Collection $^{9}, 2004$, con las que se contrasta la simplicidad de la fotografía con el impacto visual que esta ofrece [figura 9]; o la serie Altered landscapes del fotógrafo John Pfahl, 1974-1978 (Pfahl, s.d.). Dibbets continuaría con la anamorfosis en 2009 jugando con escalas superiores, pues la figura que se iba a fotografiar sería dibujada por una excavadora sobre la playa para la pieza titulada 6 Hours Tide Object with Correction of Perspective ${ }^{10}$, que referenciaría a otra intervención del año 1969: 12 Hours Tide Object with Correction on Perspective, ejecutada para el proyecto curatorial de Gerry Schum: Land Art TV. En estas piezas, se da la sensación de que el espacio capturado por la cámara se aplana, perdiéndose la profundidad, como también ocurre con la obra de Georges Rousse. Así se comprueba en sus exposiciones Georges Rousse: aquarelles et photographies, en Galerie Catherine Putman en 2019, o Georges Rousse: Le Temps retrouvé, en el Museo Ludwig de Coblence (Alemania) en 2020.
La anamorfosis en el arte contemporáneo. Un análisis de las diferentes estrategias de su aplicación en las creaciones de artistas actuales

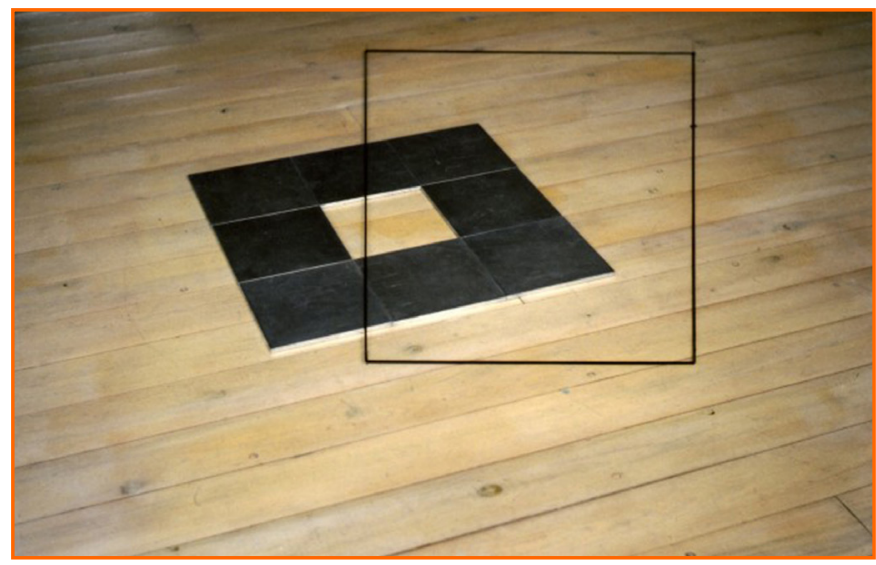

Figura 9. Jan Dibbets, Perspective Collection: Judd, 2004. Fotografía Inkjet montada en aluminio. 155 x 155 cm (aprox.). CJan Dibbets. (Pérez Art museum Miami, 2014). Fuente: https://www. pamm.org/exhibitions/new-work-jan-dibbets-perspective-collection

A diferencia de estos ejemplos, en la obra Felice Varini la pintura abstracta anamórfica es observada en el mismo espacio físico, posibilitando que el efecto óptico de la conversión del espacio tridimensional en bidimensional sea experimentado como una sensación real. Estas obras relacionadas al arte minimalista y a los proyectos site-specific, son un excelente exponente de la pintura arreferencial expandida en el espacio, que invita al observador a interactuar con él, y ofrece así múltiples lecturas de una misma realidad. Ejemplo de ello es el proyecto creado en Shanghái titulado Set of Diagonals for Cranes, 2019 [figura 10].

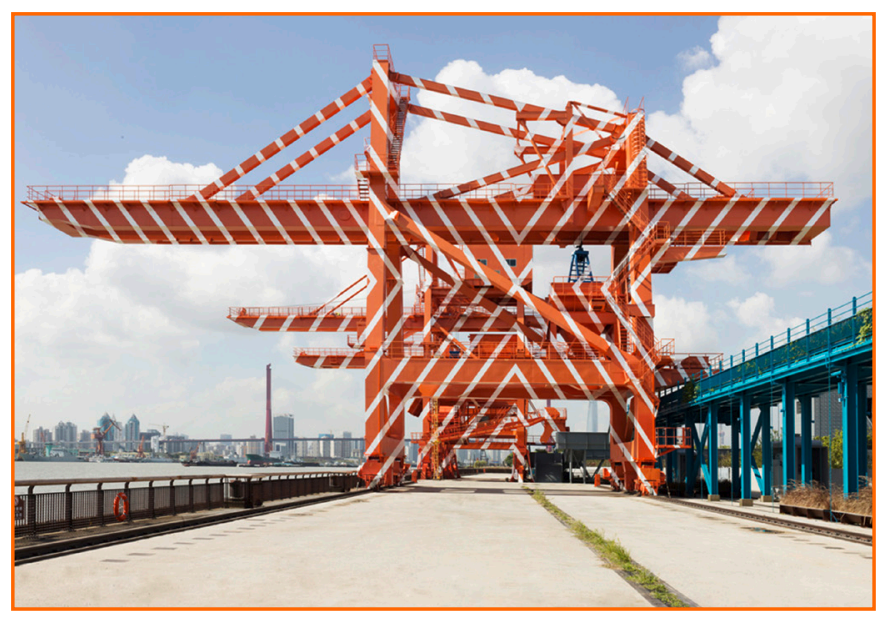

Figura 10. Felice Varini, Set of Diagonals for Cranes, 2019. Galeries Lafayette Mall, Shanghai. CFelice Varini. Fotografía cortesía del artista.

8. Esto no significa que trabajan la anamorfosis desde la fotografía, sino que exponen sus instalaciones pictóricas anamórficas a través de sus fotografías

9. Expuesta en Konrad Fischer Gallery, Colonia, 2005, y Galerie Lelong de París (Pérez Art Museum Miami, 2014).

10. Dibbets participaría en el proyecto titulado Postcapes, una serie de intervenciones artísticas en relación con un proyecto de construcción que transformaría la costa de Róterdam. 


\section{artnodes}

https://artnodes.uoc.edu

\section{Conclusiones}

Dadas las diferenciaciones entre las imágenes consideradas como quadrature y las anamórficas, llegamos a la conclusión de que las segundas no son creadas para ocultar su artificiosidad, sino que el observador es invitado a reflexionar sobre la propia imagen, solicitándose una actitud activa psíquica y físicamente, y evidenciándose su sinceridad. Si los significados de las imágenes dependen de la experiencia, desde la anamorfosis las posibilidades interpretativas se multiplican, pues el observador tiene la capacidad de situarse en tantos puntos de vista como desee.

Del análisis desarrollado sobre el empleo de la anamorfosis en el arte contemporáneo, deducimos que esta variante de la perspectiva ofrece numerosas aplicaciones. Se trata de una herramienta que diferencia y da valor a la obra de unos determinados artistas -evidenciándose sus conocimientos técnicos-cuyo discurso conceptual queda vinculado a los juicios sobre la percepción visual del espacio y sobre la incertidumbre acerca de si lo que observamos se corresponde con la realidad. Ya sea a partir de la experimentación o de la adaptación específica de los principios de los tratados a la creación contemporánea, el resultado es indudablemente enaltecedor y digno de la admiración de los observadores, tengan los artistas mayor 0 menor vinculación con el mercado del arte.

Hemos comprobado cómo el buen empleo de la anamorfosis ayuda directamente a la comprensión y la aprehensión de estos proyectos. Ya sea mediante la escultura o instalación, en la fotografía, en la pintura aplicada al espacio urbano 0 en la pintura expuesta en la galería de arte, la anamorfosis no cuestiona si el arte representa o no la realidad ya que realidad y representación son cuestionadas a través de esta. Podemos afirmar, pues, que la imagen creada desde la anamorfosis funciona como metaimagen. A través de ella podemos deducir que no existen verdades absolutas, pues se toma la imagen como jovial y efímera: «No es el tipo de imagen en la que uno puede detenerse; más bien, es como algo visto por el rabillo del ojo, visto a gran velocidad o visto a través de un ojo de cerradura» ${ }^{11}$ (Collins, 1992: 77).

La evidencia de la artificiosidad de las propias imágenes anamórficas se contrapone a la aparente naturalidad de las imágenes procedentes de los medios de comunicación y la capacidad de estas para establecer una conceptualización concreta de su significado al ir acompañadas de unos discursos determinados. En consecuencia, afirmamos que no solo la anamorfosis es una herramienta de atracción y de acercamiento del arte a la sociedad, sino que, además, invita a un replanteamiento de los dogmas establecidos. Aparece en el arte aportando un nuevo discurso acerca de la multiplicidad interpretativa que las imágenes pueden ofrecer. Factores como la
La anamorfosis en el arte contemporáneo. Un análisis de las diferentes estrategias de su aplicación en las creaciones de artistas actuales

ilusión y la ambigüedad en la imagen incentivan la apertura de un discurso hacia la reflexión crítica, una herramienta fundamental ante las fake news tan comunes en la actualidad.

En contraposición a la afirmación de Baudrillard: «Como en la anamorfosis: tiene que haber un ángulo desde el cual todo ese derroche inútil de sexo y signos cobre todo su sentido [...]» (Baudrillard, 2006: 55), consideramos que el sentido debemos encontrarlo en la confluencia de interpretaciones dadas desde todos los puntos de vista posibles. El máximo valor de la imagen está en la multiplicidad, en la interconexión de las diferentes propuestas y puntos de vista. Así lo afirma Martín Prada al referenciar a la calavera de Holbein el Joven como imagen que va más allá del dualismo preconcebido de la diferenciación entre el punto de vista preciso y el resto: «El arte, en última instancia, pues, no tanto como algo distinto que se da a ver, sino, sobre todo, como la exigencia de un tipo distinto de mirada» (Martín Prada, 2018: 54).

\section{Referencias bibliográficas}

Albrecht, Albert. 1623. Andreae Alberti zwey Bücher, das erste von der ohne und durch die Arithmetica gefundenen Perspectiva, das andere von dem dartzu gehörigen Schatten. Bey Simon Halbmayrn, Getruckt zu Nüremberg. https://doi.org/10.3931/e-rara-8283. Amnistía Internacional España. 2020. «Apple mira hacia otro lado y no aclara si hay trabajo infantil detrás de sus dispositivos». Noticias, 11 junio, 2020. https://www.es.amnesty.org/en-que-estamos/ noticias/noticia/articulo/apple-mira-hacia-otro-lado-y-no-aclarasi-hay-trabajo-infantil-detras-de-sus-dispositivos/.

Barbaro, Daniel. 1568. La pratica della perspectiva di Monsignor Daniel Barbro eletto Patriarca di Venezia, opera molto utile a Pittori, Scultori et ad Architetti. Venezia: appresso Camillo y Rutilio. https://archive.org/details/gri_33125008285765.

Baudrillard, Jean. 2005. Cultura y Simulacro. Barcelona: Kairos.

Baudrillard, Jean. 2006. El complot del arte: ilusión y desilusión estéticas. Madrid: Amorrortu.

Beever, Julian. 2018. Pavement Chalk Artist: The Three-Dimensional Drawings of Julian Beever. New York: Firefly Books.

Boa Mistura. (S. F.). BoaMistura. [Web]. http://www.boamistura.com/\#/ home.

Cabezas Jiménez, María del Mar. 2007. Imaginario Urbano. Expresión Gráfico-Plástica en el Espacio Urbano. (Tesis doctoral). Granada: Universidad de Granada.

Caus, Salomon de. 1612. La perspective, avec la raison des ombres et miroirs. Londres. Tomado de: Bibliothèque nationale de France,

11. «lt is not the kind of image one can dwell upon; rather, it is like something seen out of the corner of the eye, glimpsed at high speed or seen through a keyhole». 


\section{artnodes}

https://artnodes.uoc.edu

département Réserve des livres rares, RES-V-2000. https://gallica. bnf.fr/ark:/12148/bpt6k1172279

Collins, Daniel L. 1992. «Anamorphosis and the Eccentric Observer: Inverted Perspective and Construction of the Gaze». Leonardo, 25(1): 73-82. D0I: https://doi.org/10.2307/1575625

Da Vinci, Leonardo. 1478-1519. Codex Atlanticus. Edición consultada: Thevisualagency (s.d.), Codex Atlanticus. http://codex-atlanticus.it. Debord, Guy. 2012. La sociedad del espectáculo. Valencia: Pretextos. Dubreuil, Jean. 1642-1649. La perspective practique necessaire a tous peintres, graveurs, sculpteurs, architectes, orfevres, brodeurs, tapissiers, y autres se servans du dessein[estampe] / Par un Parisien, religieux de la Compagnie de Jesus. Chez Melchior Tavernier et Chez François L'Anglois, dit Chartres, Paris. Tomado de: (BnF), département Réserve des livres rares, RES-V-2000. https://gallica.bnf.fr/ark:/12148/btv1b55005402t.

Fontcuberta, Joan. 2016. La fura de las imágenes: Notas sobre la postfotografía. Barcelona: Galaxia Gutenberg.

González-Castro, Carmen. 2017. «Descripción del Artista». Arteinformado. https://www.arteinformado.com/guia/f/carmen-gonzalezcastro-176772.

González-Castro, Carmen y VEGAP. 2018. Carmen González Castro. http://carmengonzalezcastro.com/.

Han, Byung-Chul. 2015. La sociedad de la transparencia. Barcelona: Herder Editorial.

Hernández-Machancoses, José Luís. 2015. La anamorfosis como acontecimiento visual. Tesis Doctoral. Valencia: Universitat de València

Hurwitz, Jonty. S. F. The Art of Jonty Hurwitz. https://jontyhurwitz. com/bio

JR. 2016. JR au Louvre paris, Jr explaning his project, 2016. Vídeo. https://youtu.be/M9VkFxEwINY.

JR. s.d.. JR. https://www.jr-art.net.

Keer, Leon. 2019. Making of "offline" land art by Leon Keer. Vídeo. https://youtu.be/6j82KxEJXFY.

Kentridge, William, Fernando Francés, y María Corral. 2012. William Kentridge: ¿no se unirá usted al baile? Málaga: Centro de Arte Contemporáneo de Málaga, 14th February-13th May 2012.

Kircher, Athanasius. 1646. Ars Magna lucis et umbrae en decen libros digsesta, sumptibus. Romae: Hermanni Scheus ex typographia Ludouici Grignani.

Lomazzo, Giovanni Paolo. 1585. Trattato dell' arte della pittura, scoltura et architettura. Milán. Tomado de: Bibliothèque nationale de France, département Réserve des livres rares, RES-V-2000. https://gallica.bnf.fr/ark:/12148/bpt6k1118777.

López Montero, María Belleda. 1995. Las anamorfosis en el arte: la anamorfosis histórica como base de la investigación actual sobre las transformaciones artísticas. Tesis doctoral. Sevilla: Universidad de Sevilla. https://hdl.handle.net/11441/73887.

Maignan, Emmanuel. 1648. Perspectiva Horaria. Roma: Rossi Filippo de' imprimeur-libraire.
La anamorfosis en el arte contemporáneo. Un análisis de las diferentes estrategias de su aplicación en las creaciones de artistas actuales

Martín Prada, Juan. 2018. El ver y las imágenes en el tiempo de internet. Madrid: Ediciones Akal.

Murphy, Michael. 2019. The Immigrant - A Tribute to Immigrants. Vídeo. https://www.perceptualart.com/

Museo de Bellas Artes de Asturias. 2020. «El arte y la ciencia de la anamorfosis». Blog. Obras del mes de septiembre. 9 octubre 2017. http://www.museobbaa.com/actividad/arte-ciencia-anamorfosisfrancisco-gonzalez/.

Niceron, Jean François. 1638. La perspective curieuse ou magie artificielle des effets merveilleux: de l'optique, par la vision directe, la catoptrique, par la réflexion des miroirs plats, cylindriques y coniques, la dioptrique, par la réfraction des [...].Paris: Pierre Billaine, Tomado de: (ETH-BZ), Rar 1296/ Public Domain Mark. https://doi.org/10.3931/e-rara-13092.

Niceron, Jean François. 1646. Thaumaturgus Opticus seu Admiranda Optices, per radium directum.... Paris: François Langlois.

Noble, Tim, y Sue Webster. 2005. The new Barbarians. Málaga: Centro de Arte Contemporáneo de Málaga, abril-junio 2005.

Peeta. 2015. Peeta: spraycan art and beyond. https://www.peeta.net/. Pérez Art Museum Miami. 2014. New York: Jan Dibbets - Perspective Collection. Miami: Pérez Art Museum, July 10-0ct. 14, 2007. https://www.pamm.org/exhibitions/new-work-jan-dibbetsperspective-collection.

Pfahl, John. s.d. John Pfahl Gallery Index. https://www.josephbellows. com/exhibitions/john-pfahl2/selected-works?view=slider

Pino-León, Manuel. 2014. «Las primeras anamorfosis y Carlos V》. Bellas Artes. Revista de Artes Plásticas, Estética, Diseño e Imagen, 12: 103-119.

Sartori, Giovanni. 2008. Homo videns: La sociedad teledirigida. Bogotá: Taurus.

Schott, Gaspar. 1657. Magia Universalis Naturae et Artis. Tomo 1. Würzburg.

Short, Michael. 2017. Ask your Body - an Invitation. http://www.evanpenny.com/essay_short_ask_your_body_invitation_2017_en.php.

Silveira, Regina. 2005. Luz, Lumen. Madrid: Palacio de Cristal, mayojulio 2005.

Silveira, Regina. s.d. Regina Silveira. https://reginasilveira.com/. Vattimo, Gianni. 1996. La sociedad transparente. Barcelona: Paidós. Vignola, Giacomo Barozzi da, y Egnatio Danti. 1583. Le due regole della prospettiva pratica. Roma: Francesco Zannetti. Tomado de: Internet Archive. https://archive.org/details/dveregoledellapr00vign/ page/n3/mode/2up.

Wenner, Kurt. 2019. Kurt Weener. Master Artist. https://kurtwenner.com/.

Zanela, Augusto. 2011. Augusto Zanela. (Porfolio del artista). https:// www.linkedin.com/in/augustozanela/detail/overlay-view/ urn:li:fsd_profileTreasuryMedia:(ACoAAAILdzEBDGwvIUVM25xE w9cDmyJPj9T8jAE,50789267)/

Zoer. s.d. Zoer. https://www.zoerism.com/mural-support-grandesurface. 


\section{artnodes}

https://artnodes.uoc.edu
La anamorfosis en el arte contemporáneo. Un análisis de las diferentes estrategias de su aplicación en las creaciones de artistas actuales

\section{CV}

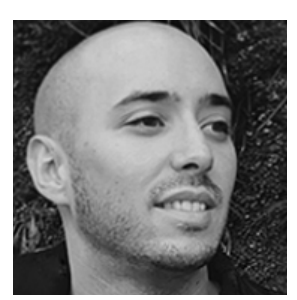

Jose-Antonio Soriano-Colchero

Universidad de Granada

joseasoriano@ugr.es

Doctor por la Universidad de Granada, menciones Cum Laude y doctor internacional, artista multidisciplinar, docente e investigador del Departamento de Dibujo en la Facultad de Bellas Artes de la Universidad de Granada desde 2016. Adscrito al Grupo de Investigación Hum866: Dibujo y Proyecto. Actualmente colabora en proyecto (ARS\&URBS) Representación pictórica de la ciudad. Del Siglo xvI al Siglo xIx: Perspectivas, corografías y panoramas (HAR2016-78298-P). Estancia internacional en la Università di Roma La Sapienza (2018). Su investigación está especializada en el estudio teórico-práctico (histórico y actual) de los principales sistemas de representación del espacio aplicados a las artes plásticas en función de los contextos espacio-temporales, enfocando dichos conocimientos al arte contemporáneo. Autor de varias publicaciones en revistas, capítulos de libro, así como participaciones en congresos internacionales. Su producción artística ha sido publicada en catálogos de exposiciones individuales y colectivas. 